\title{
Habitações para famílias de baixa renda: estratégias de implantação de assistência pública gratuita
}

Housing for low-income families: strategies for implementing free public assistance Vivienda para familias de bajos ingresos: estrategias para implementar asistencia pública gratuita

Recebido: 18/04/2020 | Revisado: 20/04/2020 | Aceito: 30/04/2020 | Publicado: 06/05/2020

\begin{abstract}
Almir Antônio Vieira
ORCID: http://orcid.org/0000-0003-3378-1758

Universidade do Estado de Minas Gerais - Unidade João Monlevade, Brasil

E-mail: almir.vieira@uemg.br

Thainá Prando Basto

ORCID: http://orcid.org/0000-0002-9108-8874

Universidade do Estado de Minas Gerais - Unidade João Monlevade, Brasil

E-mail: thainaprandobastos@ hotmail.com
\end{abstract}

\section{Resumo}

A moradia digna é um direito de todo cidadão brasileiro resguardado pela Constituição da República Federal, todavia estima-se que 7,77 milhões de habitações são deficientes em vista das necessidades básicas das famílias brasileiras. A fim de combater ao elevado índice de déficit habitacional existente, a Lei Federal $n^{\circ} 11.888$ asseguram às famílias de baixa renda assistência técnica pública e gratuita, como projetos e execução de serviços técnicos no âmbito da engenharia, arquitetura e urbanismo. O presente artigo tem como objetivo apresentar estratégias de implantação da assistência técnica pública e gratuita às famílias de baixa renda visando o projeto e a construção de habitações de interesse social. A idealização de um sistema social de auxílio à provisão de habitações está diretamente relacionada à garantia de qualidade de vida à população que, em maior parte, recorre à autoconstrução como forma de produção da moradia. A metodologia utilizada no estudo foi levantamento bibliográfico, pesquisa documental e estudos de casos práticos de sucesso. Como resultado final, são apresentadas propostas para a implantação da assistência técnica pública e gratuita a 
famílias de baixa renda, e consequentemente, construção de habitações de interesse social, destacando para cada uma delas os fatores de viabilidade técnica e econômica.

Palavras-chave: Moradia; Baixa renda; Construção; Viabilidade.

\begin{abstract}
Decent housing is a right of every Brazilian citizen protected by the Constitution of the Federal Republic, however it is estimated that 7.77 million homes are deficient in view of the basic needs of Brazilian families. In order to combat the high rate of existing housing deficit, Federal Law 11888 provides public and free technical assistance to low-income families, such as projects and execution of technical services in the scope of engineering, architecture and urbanism. The idealization of a social system to assist in the provision of housing is directly related to the guarantee of quality of life for the population that, for the most part, uses selfconstruction as a form of housing production. The methodology used in the study was bibliographic survey, documentary research and successful case studies. As a final result, proposals are presented for the implementation of free public technical assistance to lowincome families, and consequently, construction of social housing, highlighting the factors of technical and economic viability for each one.
\end{abstract}

Keywords: Home; Low income; Construction; Viability.

\title{
Resumen
}

La vivienda digna es un derecho de todos los ciudadanos brasileños protegidos por la Constitución de la República Federal, sin embargo, se estima que 7.77 millones de hogares son deficientes en vista de las necesidades básicas de las familias brasileñas. Para combatir la alta tasa de déficit habitacional existente, la Ley Federal 11888 brinda asistencia técnica pública y gratuita a familias de bajos ingresos, como proyectos y ejecución de servicios técnicos en el ámbito de la ingeniería, la arquitectura y el urbanismo. La idealización de un sistema social para ayudar en la provisión de vivienda está directamente relacionada con la garantía de calidad de vida para la población que, en su mayor parte, utiliza la autoconstrucción como una forma de producción de vivienda. La metodología utilizada en el estudio fue la encuesta bibliográfica, la investigación documental y los estudios de casos exitosos. Como resultado final, se presentan propuestas para la implementación de asistencia técnica pública y gratuita a familias de bajos ingresos y, en consecuencia, la construcción de viviendas sociales, destacando los factores de viabilidad técnica y económica para cada uno.

Palabras clave: Casa; De bajos ingresos; Construcción; Viabilidad. 


\section{Introdução}

A moradia é um direito social de todo cidadão brasileiro, resguardado pelo artigo $6^{\circ}$ da Constituição da República Federativa do Brasil de 1988 e pelo artigo $2^{\circ}$ do Estatuto das Cidades disposto na Lei Federal no 10.257 de 2001. Para efetivar a legislação nacional, ao longo dos anos surgiram alguns tipos de políticas públicas habitacionais como o programa Minha Casa Minha Vida, a regularização fundiária e a desapropriação por interesse social para concessão de uso com fins de moradia (Lis, 2019).

A fim de garantir a moradia aos desamparados, em 24 de dezembro de 2008, foi sancionada a Lei Federal $\mathrm{n}^{\mathrm{o}}$ 11.888, que tem como objetivo diminuir o elevado déficit habitacional existente no Brasil. Essa lei assegura às famílias de baixa renda assistência técnica pública e gratuita, como projetos e execução de serviços técnicos no âmbito da engenharia, arquitetura e urbanismo.

Segundo a Diretoria de Estatísticas e Informações da Fundação João Pinheiro (2015), a deficiência no setor habitacional é correlacionada diretamente às moradias inadequadas à habitação, em razão da precariedade das construções ou do desgaste da estrutura física. $\mathrm{O}$ déficit habitacional inclui também a necessidade de aumentar o estoque de moradias para famílias que pretendem constituir um domicílio, ou seja, pessoas de baixa renda que têm dificuldade de pagar aluguel nas áreas urbanas e vivem em casas e apartamentos alugados com uma grande densidade de pessoas, e também moradia em imóveis e locais não residenciais.

Em 2017, a Fundação Getúlio Vargas estimou que 7,77 milhões de habitações são deficientes em vista das necessidades básicas das famílias brasileiras. Analisando o déficit habitacional no Brasil, o estado de Minas Gerais possui o segundo maior déficit habitacional do País, totalizando 575.478 domicílios, sendo aproximadamente 94\% desses imóveis localizados em zonas urbanas (FJP, 2016; FGV, 2018).

A necessidade de implantar um sistema social de auxílio à construção da habitação está diretamente relacionada à garantia de qualidade de vida à população desamparada pelo Estado. O planejamento e a construção desses espaços por profissionais legalmente habilitados refletem no uso racional da parcela de solo urbana, asseguram o cumprimento da legislação urbanística e ambiental e evitam a ocupação de áreas de risco, diminuindo as despesas com problemas relacionados à infraestrutura urbana. Apesar da previsão legal de mecanismos para assegurar o direito dos cidadãos brasileiros à moradia, não existe efetividade por parte do poder público nas ações de implantação (Soares, 2016). 
Dessa forma, o objetivo deste estudo é propor estratégias de implantação da assistência técnica pública e gratuita às famílias de baixa renda visando o projeto e a construção de habitações de interesse social.

Para consecução dessa etapa foi necessária atender aos seguintes itens específicos: apresentar a importância da implantação da Lei Federal $\mathrm{n}^{\mathrm{o}}$ 11.888/2008, investigar a complexidade da implementação da Lei Federal $n^{\circ} 11.888 / 2008$, e sugerir um sistema de implantação da assistência técnica pública e gratuita nos municípios.

\section{Referencial Teórico}

\subsection{Contextualização}

A habitação adequada é um direito fundamental de todo ser humano e sua família, prevista na Declaração Universal dos Direitos Humanos de 10 de dezembro de 1948 e no Pacto Internacional dos Direitos Econômicos, Sociais e Culturais de 16 de dezembro de 1966, adotados e proclamados pela Organização das Nações Unidas (ONU/BR, 2016).

As primeiras iniciativas de políticas públicas brasileiras para a produção de moradias surgiram na década de 1930 impulsionadas pela industrialização e pela urbanização durante o governo do presidente Getúlio Vargas (1930-1945). Em 1946, no governo Gaspar Dutra (1946-1951), foi criado a Fundação da Casa Popular (FCP), sendo considerado o primeiro órgão nacional destinado a prover moradia popular. A FCP recebeu maior investimento durante o governo de Juscelino Kubitschek (1956-1961) onde houve o maior número de unidades habitacionais construídas.

Em quase 18 anos de existência, o Estado não cumpriu com a proposta inicial da FCP, tendo em vista a escassez de moradia e a inconstância de recursos, resultando na construção de apenas 17.000 habitações ao longo de todo esse período.

O fracasso da FCP pode ser explicado pelo caráter emergencial e pontual das ações, uma vez que o principal objetivo era derivar dividendos políticos, quer sob a forma de votos, quer de prestígio (Azevedo \& Andrade, 1982; Motta, 2011).

Em 1964, o golpe militar provocou a extinção da FCP e a criação do Plano Nacional de Habitação para consolidar o capital industrial brasileiro. O fortalecimento da construção civil foi uma estratégia utilizada para dinamizar a economia do Brasil, visando proporcionar a geração de empregos e a estabilidade social. A fim de operacionalizar os recursos destinados 
ao Plano Nacional de Habitação, advindos do Fundo de Garantia por Tempo de Serviço (FGTS) e das cadernetas de poupança, foi criado o Banco Nacional de Habitação (BNH).

Para receber os investimentos do BNH foram criadas as Companhias de Habitação Popular (COHABs), que consistiam em empresas públicas ou mistas destinadas à execução de políticas para promover a redução do déficit habitacional. Entre 1964 e 1969, realizou-se a implantação e expansão das COHABs, considerando o financiamento de moradias para o mercado popular. Entre 1970 e 1974, a diminuição do poder de compra do salário mínimo aumentou o número de inadimplentes tornando o plano do governo insustentável. Entre 1975 e 1980, houve uma reestruturação das COHABs com o aumento da produção de unidades habitacionais destinadas à classe média (Motta, 2011).

O objetivo principal do Plano Nacional de Habitação era a produção de moradias para a população de baixa renda a fim de controlar o crescimento das ocupações irregulares, entretanto, a construção de conjuntos habitacionais às margens das cidades, devido aos baixos custos dos terrenos, ignorava a ausência de infraestrutura urbana e alimentava o crescimento das favelas.

Além disso, os financiamentos atingiram principalmente a classe média emergente, excluindo os trabalhadores com renda menor que um salário mínimo que deveriam ser os principais beneficiados. Ao todo foi construida quatro milhões de habitações, número expressivo para a realidade do país, mas que não resolveu o problema. O BNH foi extinto em 1986 com a redemocratização brasileira e as suas funções foram transferidas para a Caixa Econômica Federal.

Em 1987, durante o governo de José Sarney (1985-1990), foi criado o Programa Nacional de Mutirões Habitacionais que tinha como objetivo financiar moradias para famílias com renda de até três salários mínimos. O programa não alcançou suas metas devido à alta inflação e ineficiência da gestão (Motta, 2011).

O Congresso Nacional decretou em 13 de julho de 1993, a Lei Federal nº 8.677, que dispõe sobre o Fundo de Desenvolvimento Social (FDS) destinado ao financiamento de projetos de investimento de interesse social nas áreas de habitação popular de inciativa de pessoas físicas e de empresas ou entidades do setor privado; e instituiu o Conselho Curador do FDS (Brasil, 1993).

Na década de 1990, entretanto, as políticas habitacionais não obtiveram resultados efetivos e/ou expressivos. 
No Governo Collor (1990-1992), o mais importante programa habitacional lançado foi o PAIH (Plano de Ação Imediata para a Habitação), que propunha o financiamento de 245 mil habitações em 180 dias, mas não cumpriu suas metas. O governo Itamar (1992 a 1994) criou os Programas Habitar Brasil e Morar Município, que tinham como objetivo financiar a construção de moradias para população de baixa renda, a serem construídas em regime de "ajuda mútua". Todavia, esses Programas tinham uma padronização excessiva e muitas exigências legais, o que impedia muitos municípios de captarem os recursos disponibilizados (Motta, 2011).

O planejamento habitacional tornou-se, portanto, imprescindível para possibilitar aos estados e municípios a constituição dos Planos Locais de Habitação de Interesse Social (PLHIS) e identificação das Zonas Especiais de Interesse Social (ZEIS), necessários para definição das diretrizes da gestão pública e dos protagonistas sociais, considerando as características locais.

Em 2003, o governo de Luiz Inácio Lula da Silva (2003-2010) criou o Ministério das Cidades para combater as desigualdades sociais, ampliando o acesso da população a infraestrutura urbana. Em 2004, a fim de promover uma gestão democrática da Política Nacional de Desenvolvimento Urbano (PNDU), criou o Conselho das Cidades (ConCidades) que representou a consolidação de um importante instrumento de consulta e deliberação acerca das políticas executadas pelo Ministério das Cidades nas áreas de habitação, saneamento, transporte, mobilidade urbana e planejamento territorial.

A Secretária Nacional de Habitação do Ministério das Cidades tornou-se responsável pelos programas relacionados à moradia, divididos em dois grupos: produção e aquisição de novas moradias e urbanização de assentamentos precários.

Quase 20 anos após a extinção do BNH, sancionou a Lei Federal n 11.124, de 16 de junho de 2005, que tem como objetivo principal determinar os agentes responsáveis pela implantação de ações e programas voltados para habitação e de infraestrutura urbana, tornando-se um marco no compromisso do governo de assegurar esse direito a população de menor renda. Esta lei dispõe sobre o Sistema Nacional de Habitação de Interesse Social (SNHIS), instituído para viabilizar, implementar e articular o acesso a terra urbanizada e à residência digna e sustentável (Brasil, 2005).

No sistema, o Ministério das Cidades passou a ser o órgão central amparado pelos Conselhos das Cidades e pelos Conselhos, Órgãos e Instituições da Administração Pública. A lei também estabeleceu o Fundo Nacional de Habitação de Interesse Social (FNHIS) que gerencia os recursos financeiros dos programas de Urbanização de Assentamentos 
Subnormais e de Habitação de Interesse Social, operados pela Caixa Econômica Federal; e instituiu o Conselho Gestor do FNHIS.

O planejamento habitacional tornou-se, portanto, imprescindível para possibilitar aos estados e municípios a constituição dos Planos Locais de Habitação de Interesse Social (PLHIS) e identificação das Zonas Especiais de Interesse Social (ZEIS), necessários para definição das diretrizes da gestão pública e dos protagonistas sociais, considerando as características locais (Cardoso, 2008).

Definidos os papéis dos agentes nas esferas federais, estaduais e municipais na instrumentalização das políticas habitacionais, a Lei Federal n ${ }^{\circ} 11.888$, de 24 de dezembro de 2008, conhecida como Lei da Engenharia Pública. Ela foi sancionada especialmente para garantir às famílias de baixa renda o acesso à assistência técnica para serviços de construção, reforma e ampliação de suas edificações, realizados por profissionais legalmente habilitados de engenharia e arquitetura.

A assistência técnica é uma estratégia fundamental para a viabilização de uma parte da produção habitacional, em especial para o desenvolvimento de cooperativas e associações promotoras de habitação e para os autoconstrutores, uma vez que boa parte de prefeituras e estados não possui quadros técnicos de apoio para suprir esta orientação. Esse é um dos principais recursos que podem ser utilizados para ampliar qualificadamente o atendimento das necessidades habitacionais das populações de baixarenda (Brasil, 2009).

A fim de efetivar a Política Nacional de Habitação (PNH), a Secretaria Nacional de Habitação (SNH) lançou um novo Plano Nacional de Habitação (PlanHab) em 2009 que constituiu um projeto de longo prazo para o setor habitacional com metas de avanços institucionais e produção física vinculados a um planejamento orçamentário- financeiro, a fim de universalizar à moradia digna para todo cidadão brasileiro.

Em 2009, o governo lançou o Programa Minha Casa Minha Vida (MCMV), que foi a maior iniciativa governamental realizada para possibilitar o acesso à casa própria pelas famílias brasileiras.

Durante os 10 anos de programa (2009-2019), foram contratados cerca de 5,5 milhões de unidades habitacionais e entregues mais de 4 milhões. Além disso, o MCMV gerou em torno de 3,5 milhões de empregos no setor da construção civil (Câmara Brasilieira da Indústria da Construção apud Lis, 2019). 
(CC BY 4.0) | ISSN 2525-3409 | DOI: http://dx.doi.org/10.33448/rsd-v9i7.3770

O objetivo principal do programa foi criar um ambiente favorável ao crescimento econômico brasileiro por meio do desenvolvimento do mercado habitacional e de crédito, bem como a geração de emprego e renda.

Em 2010, foi desenvolvido pelo Instituto de Arquitetos do Brasil (IAB, 2010), o Manual de "Implantação da Assistência Técnica Pública e Gratuita a Famílias de Baixa Renda para Projeto e Construção de Habitação de Interesse Social”. Este documento apresenta possíveis mecanismos de implementação fundamentados na Lei Federal $\mathrm{n}^{\circ}$ 11.888/08, a fim de possibilitar a relação direta do engenheiro ou arquiteto com o beneficiado.

Em 2015, uma pesquisa realizada pelo Instituto Datafolha encomendada pelo CAU/BR, revelou que dentre a população economicamente ativa que já construiu ou reformou, $85,40 \%$ da população dispensou a contratação de engenheiros e arquitetos para construção ou reforma de suas casas, realizando o serviço por conta própria ou contratando serviços de pedreiros, mestre de obras, amigos e parentes. Somente $14,60 \%$ contrataram profissionais legalmente habilitados para execução das atividades técnicas, conforme Figura 1.

Figura 1 - Pesquisa do CAU/BR e Instituto Datafolha

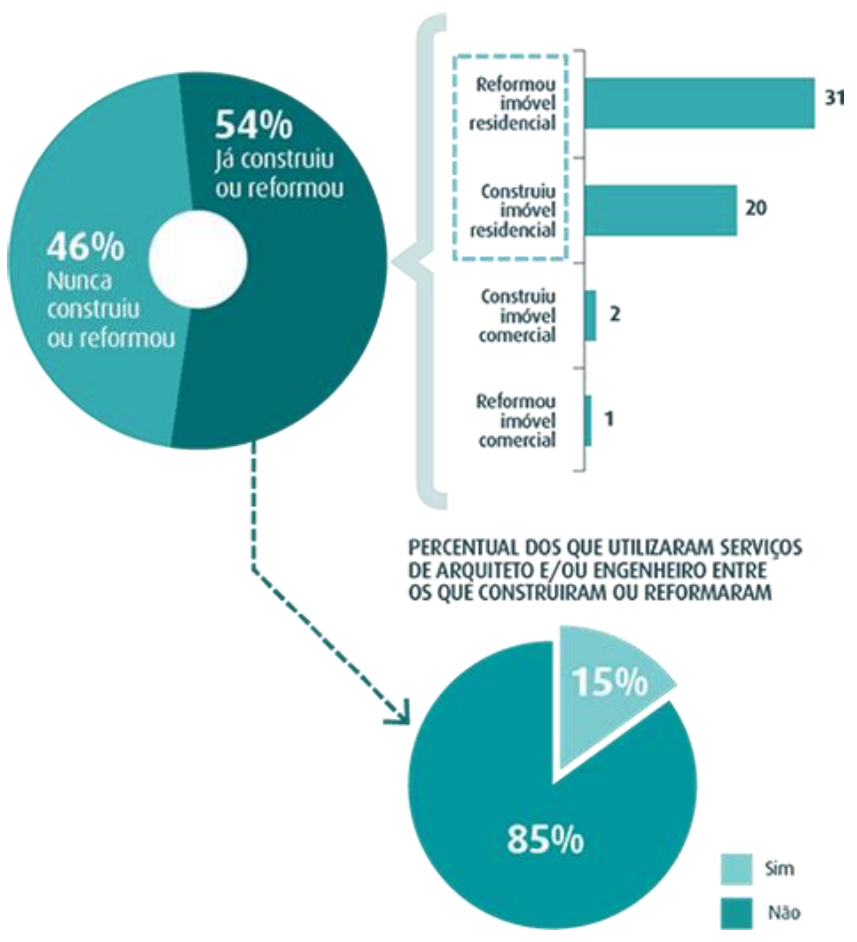

Fonte: CAU/BR (2015). 
Analisando de forma geral, a pesquisa concluiu que:

[...] a contratação de profissionais especializados está ligada à renda e à escolaridade. Enquanto 26,2\% da população economicamente ativa com nível superior construíram ou reformou com ajuda especializada, esse índice é de $9,50 \%$ para a população com nível de escolaridade fundamental. Entre as pessoas de classes A e B, o índice de utilização de profissionais tecnicamente habitados é de $25,80 \%$. Apenas entre as pessoas da classe A, essa taxa pula para 55,30\% (CAU/BR; Instituto DataFolha, 2015).

É importante ressaltar também que o déficit habitacional brasileiro foi estimado em 7,77 milhões de unidades habitacionais, em 2017 (FGV, 2018). Esse número representa um recorde nos estudos apresentados nos últimos 10 anos, conforme demonstrado no Gráfico 1.

Diante desse cenário, as estatísticas sobre a relação existente entre as famílias de menor renda e baixa escolaridade, e a contratação de profissionais legalmente habilitados (Figura 1). Assim, o crescimento do déficit habitacional nos últimos 10 anos (Gráfico 1), reforça a falta de efetividade nas ações do poder público no desenvolvimento do setor de habitação de interesse social e na universalização das profissões correlacionadas.

Gráfico 1- Evolução do Déficit Habitacional Total.

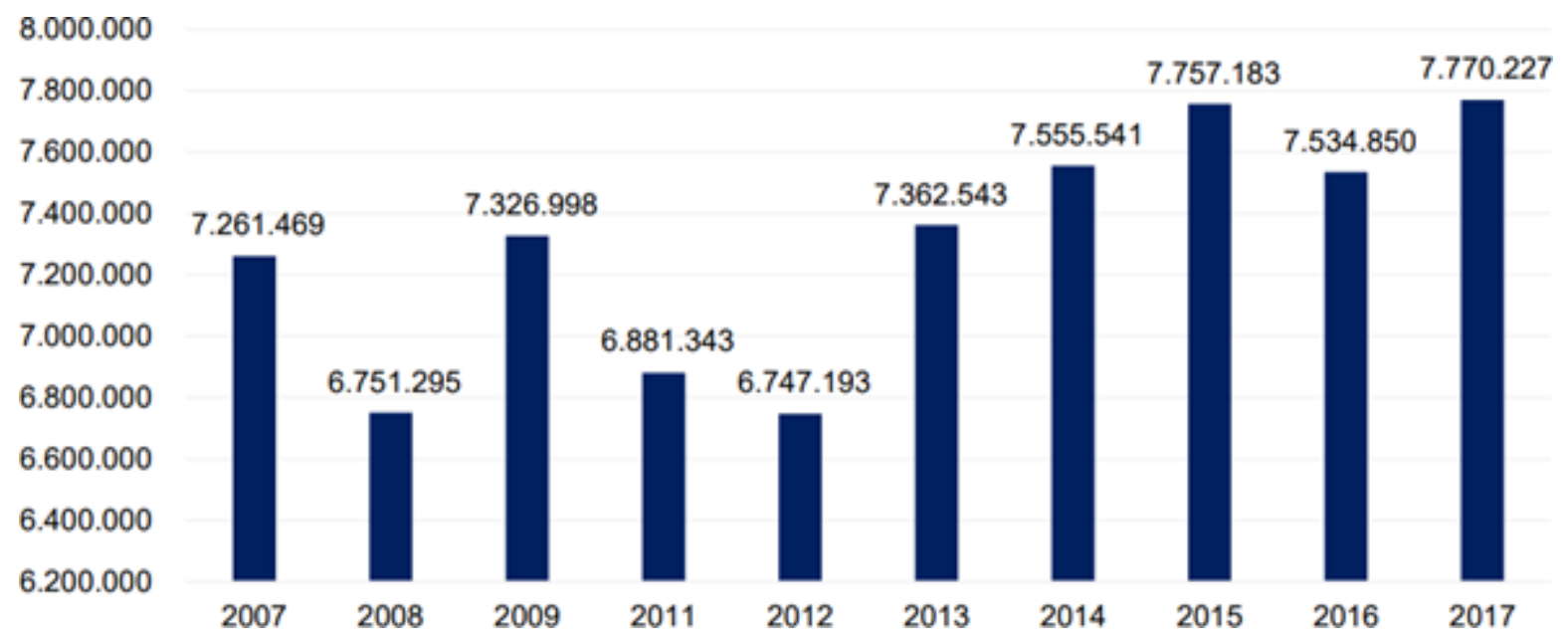

Fonte: FGV (2018) 


\subsection{Assistência pública e gratuita}

Segundo a FGV (2018), os segmentos de investimentos ao curto prazo compõem $57,7 \%$ do déficit habitacional brasileiro, os outros $42,3 \%$, o ônus excessivo com aluguel. Esses dados podem ser observados na Tabela 1, e reforçam a necessidade de aplicação prioritária de recursos nas áreas de habitação precária, coabitação familiar e adensamento excessivo.

Tabela 1- Déficit habitacional e seus componentes (Ano 2017).

\begin{tabular}{|c|c|c|}
\hline Componentes & Número de unidades & Participação relativa \\
\hline Habitação precária & $\mathbf{9 6 7 . 2 7 0}$ & $\mathbf{1 2 , 4 \%}$ \\
\hline Improvisados & 161.710 & $2,1 \%$ \\
\hline Rústicos & 805.560 & $10,4 \%$ \\
\hline Coabitação familiar & $\mathbf{3 . 2 0 9 . 2 9 9}$ & $\mathbf{4 1 , 3 \%}$ \\
\hline Cômodos & 117.350 & $1,5 \%$ \\
\hline Famílias conviventes & 3.091 .949 & $39,8 \%$ \\
\hline Ônus excessivo com aluguel & $\mathbf{3 . 2 8 9 . 9 4 8}$ & $\mathbf{4 2 , 3 \%}$ \\
\hline Adensamento excessivo & $\mathbf{3 0 3 . 7 1 1}$ & $\mathbf{3 , 9 \%}$ \\
\hline Déficit Total & $\mathbf{7 . 7 7 0 . 2 2 7}$ & $\mathbf{1 0 0 , 0 \%}$ \\
\hline
\end{tabular}

Fonte: FGV (2018)

De acordo com o $\S 5^{\circ}$, artigo $31^{\circ}$, contidos na Lei Federal $n^{\circ} 9.936 / 98$, entende-se como famílias de baixa renda, as famílias com renda mensal inferior a 5(cinco) salários mínimos e que não possuem imóvel urbano ou rural.

Analisando a distribuição do déficit habitacional brasileiro fica evidente a necessidade de priorizar os investimentos em políticas habitacionais para as famílias de menor renda. Essa afirmação é constatada no resultado do Gráfico 2, da pesquisa da Fundação Getúlio Vargas (FGV, 2018). 
Research, Society and Development, v. 9, n. 7, e167973770, 2020

(CC BY 4.0) | ISSN 2525-3409 | DOI: http://dx.doi.org/10.33448/rsd-v9i7.3770

Gráfico 2 - Distribuição relativa do déficit habitacional por faixa de renda familiar.

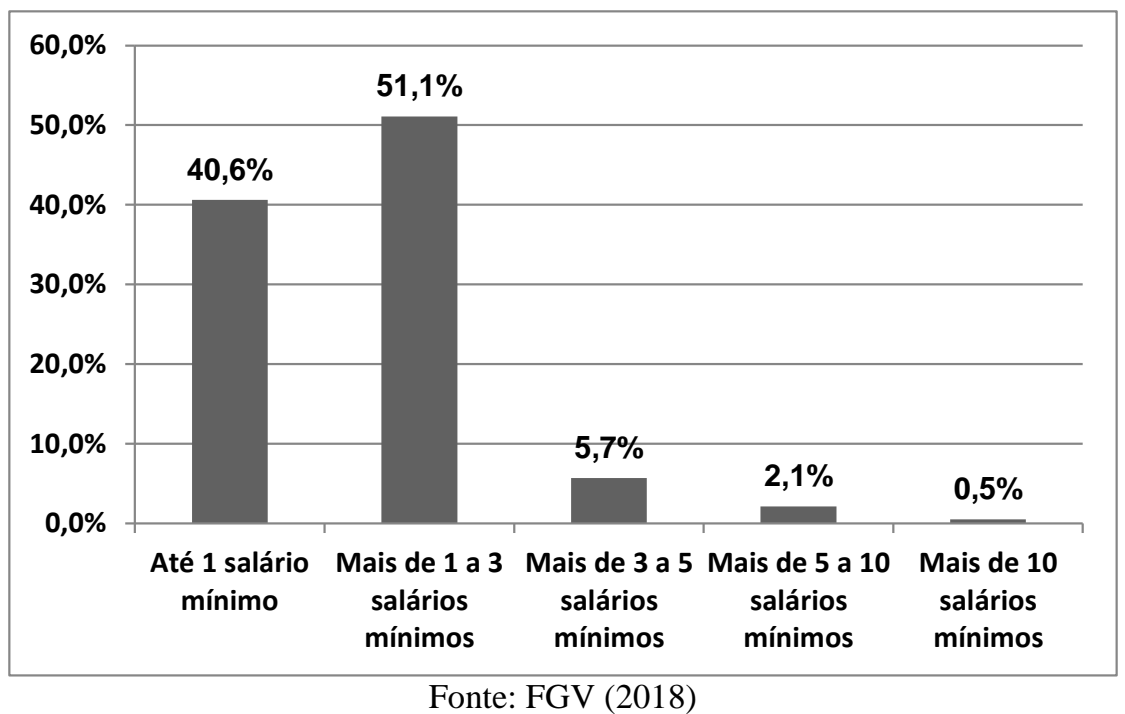

Observa-se que o número de famílias que possuem renda mensal de até 3(três) salários mínimos corresponde a 91,7\%, ou seja, em termos de unidades com déficit habitacional esse número equivale a 7,1 milhões.

$\mathrm{O}$ artigo $3^{\circ}$ da Lei Federal $n^{\circ} 11.888$ de 24 de dezembro de 2008, determina:

Art. $3^{\circ}$ A garantia do direito previsto no art. $2^{\circ}$ desta Lei deve ser efetivada mediante o apoio financeiro da União aos Estados, ao Distrito Federal e aos Municípios para a execução de serviços permanentes e gratuitos de assistência técnica nas áreas de arquitetura, urbanismo e engenharia (Brasil, 2008).

“Os municípios são responsáveis pelo envio de propostas à União para fins de seleção e consequente repasse de recursos para a prestação dos serviços de assistência técnica, assim como a prestação de contas ao final do processo" (IAB, 2010).

\subsubsection{Papel dos Municípios}

Como fundamentação prática de aplicabilidade, esse estudo utiliza o municipio de João Monlevade, localizado na região Leste (Vale do Aço), no estado de Minas Gerais. O município possui uma população estimada de 79.387 pessoas de acordo com dados apresentados pelo Instituto Brasileiro de Geografia e Estatística em 2018, e densidade demográfica de 742,35 habitantes por $\mathrm{km}^{2}$ em concordância com os dados do censo demográfico (IBGE, 2010). 
No que tange ao setor habitacional, a Lei Municipal $\mathrm{n}^{\circ} 1.572$ promulgada em 15 de abril de 2003, dispõe sobre a habitação de interesse social, institui o Fundo Municipal de Habitação $(\mathrm{FMH})$ e normatiza o Conselho Municipal de Habitação do município de João Monlevade.

Em 2013, a prefeitura municipal de João Monlevade apresentou o Plano Local de Habitação de Interesse Social (PLHIS) para a população com o objetivo principal de "estabelecer os programas e ações específicas que viabilizem a produção de novas moradias, recolocações de habitações em áreas de risco, bem como promover a regularização fundiária no território municipal" (PMJM/MG, 2013).

O município de João Monlevade caracteriza-se ainda por possuir loteamentos irregulares e/ou clandestinos e ocupações de terrenos ou prédios por movimentos de moradia. O município não possui favelas, mocambos, palafitas ou assemelhados e cortiços, casas de cômodo ou cabeças-de-porco (IBGE, 2017b).

Além disso, em 2015 e/ou 2016 foi identificado que a prefeitura realizou a construção, aquisição e melhoria de unidades habitacionais, oferta de lotes, regularização fundiária e urbanização de assentamentos (IBGE, 2017).

\subsubsection{Papel do Profissional Legalmente Habilitado}

Os projetos e a execução das obras exigem que os responsáveis estejam legalmente habilitados em seus conselhos profissionais, e consequentemente, qualificados para trabalhar com a assistência técnica pública e gratuita.

O Manual "Implantação da Assistência Técnica Pública e Gratuita a Famílias de Baixa Renda para Projeto e Construção de Habitação de Interesse Social” propõe que cada usuário será atendido por um profissional legalmente habilitado, que apresentará soluções de maior qualidade arquitetônica e atenderá às especificidades de cada cliente.

A independência do profissional é fundamental para a autonomia das famílias e para a obtenção de serviços personalizados de acordo com as necessidades dos clientes (IAB, 2010).

Conhecido mundialmente pela sua atuação em habitações de interesse social, Aravena (2017), ressalta que nos dias de hoje o papel do arquiteto é convocado a servir necessidades sociais e humanitárias. 


\subsubsection{Papel dos Conselhos Profissionais}

O Conselho Federal de Engenharia e Agronomia (CONFEA), o Conselho de Arquitetura e Urbanismo do Brasil (CAU/BR) e o Conselho Federal dos Técnicos Industriais (CFT) são autarquias públicas federais que têm o papel de regulamentar e fiscalizar o exercício das atividades profissionais das áreas afetas a engenharia e a arquitetura em defesa da sociedade. Essas entidades são compostas por instâncias estaduais, representadas no estado de Minas Gerais pelo Conselho Regional de Engenharia e Agronomia de Minas Gerais (CREA/MG), pelo Conselho de Arquitetura e Urbanismo de Minas Gerais (CAU/MG) e pelo Conselho Regional dos Técnicos Industriais de Minas Gerais (CRT/MG).

\subsubsection{Papel das Universidades}

A Universidade do Estado de Minas Gerais (UEMG), unidade João Monlevade, foi instalada no município de João Monlevade em setembro de 2006. Atualmente, a Universidade possui em torno mil alunos, e oferece gratuitamente os cursos de engenharia ambiental, de minas, metalúrgica e civil.

Ressalta-se que o curso de engenharia civil oferece aos alunos uma formação profissional sólida e atualizada nas áreas de planejamento, projeto, orçamento, cálculo e execução de obras, bem como na solução dos problemas ambientais decorrentes das atividades da construção (UEMG, 2019).O estabelecimento de um convênio ou termo de parceria com a UEMG, Unidade João Monlevade, propiciará o incentivo à pesquisa, à incorporação de tecnologias alternativas e sustentáveis aos projetos, e a capacitação de mão-de-obra qualificada para produção de habitações em regime de mutirão ou autogestão na comunidade.

As atividades seriam desenvolvidas de forma voluntária não remunerada ou, quando possível, por meio de bolsas de estudo disponibilizadas aos alunos que desenvolvem atividades de pesquisa e extensão sob a tutela de um professor (CAU/BR; CAU/SC, 2018). A interação entre a universidade, prefeitura, entidade de classe e sociedade provocará um impacto direto na melhoria da qualidade de vida das famílias beneficiadas pela assistência técnica. 


\section{Metodologia}

Este projeto foi desenvolvido por meio de uma pesquisa aplicada, visando aprimorar as informações e identificar perspectivas para implantação de assistência técnica pública e gratuita a famílias de baixa renda em habitações de interesse social, tendo o município de João Monlevade/MG como o caso prático.

Pesquisas de natureza aplicada têm como característica fundamental a produção de conhecimentos práticos (Gil, 2008), a fim de transformar em ação concreta os resultados do projeto desenvolvendo soluções para problemas específicos.

O caráter exploratório é considerado, pois este estudo tem "como principal finalidade desenvolver, esclarecer e modificar conceitos e ideias, tendo em vista a formulação de problemas mais precisos ou hipóteses pesquisáveis para estudos posteriores” (Ibid, 2008).

Para realização desta investigação foram utilizados procedimentos técnicos auxiliados por métodos bibliográficos e documentais vinculados a estudos de casos em municípios onde foi implantada a assistência técnica pública e gratuita.

A pesquisa bibliográfica fez-se necessária para analisar contribuições técnicas sobre o tema, esclarecendo o conteúdo a partir de manuais e referências teóricas publicadas. Já a pesquisa documental, caracteriza-se pela análise de informações provenientes de documentos relacionados ao assunto. Ela foi utilizada principalmente para investigar informações a serem coletadas junto à Prefeitura Municipal de João Monlevade acerca de políticas remotas sobre habitações de interesse social.

A pesquisa documental assemelha-se muito à pesquisa bibliográfica. A única diferença entre ambas está na natureza das fontes. Enquanto a pesquisa bibliográfica se utiliza fundamentalmente das contribuições dos diversos autores sobre determinado assunto, a pesquisa documental vale-se de materiais que não receberam ainda um tratamento analítico, ou que ainda podem ser reelaborados de acordo com os objetivos da pesquisa (Gil, 2008).

Considerando a necessidade de analisar estratégias de implantação da assistência técnica pública e gratuita tornou-se necessário realizar estudos de casos para ampliar e aprofundar os conhecimentos relacionados a contextos em que este auxílio foi ofertado a população de baixa renda.

O estudo de caso "é um estudo empírico que investiga um fenômeno atual dentro do seu contexto de realidade, quando as fronteiras entre o fenômeno e o contexto não 
são claramente definidas e no qual são utilizadas várias fontes de evidência" (Yin, 2005 apud Gil, 2008).

Finalmente, a análise do conteúdo foi qualitativa, tendo em vista que o objetivo final deste trabalho é propor uma estratégia de que poderá vir a resultar na oferta de assistência técnica pública e gratuita em habitações de interesse social para famílias de baixa renda.

A pesquisa qualitativa, por sua vez, busca aprofundar sua compreensão com diferentes abordagens sobre dados não métricos de forma que o objetivo da amostra seja produzir novas informações (Gerhardt \& Silveira, 2009).

Os materiais e métodos foram realizados em duas (2) partes divididas em levantamento e interpretação dos dados. A fase de levantamento de dados envolveu o levantamento bibliográfico, a pesquisa documental e os estudos de casos.

\section{Resultados e Discussão}

Os casos selecionados para estudos comparativos foram:

1) Programa "Planta Popular", implementado pela Prefeitura Municipal de Uberlândia/MG, tendo o poder público municipal como principal protagonista (PMU/MG, 2017);

2) Programa de "Assistência Técnica Pública e Gratuita em Habitação" desenvolvida pela Associação dos Engenheiros, Arquitetos e Agrônomos da Região de Alfenas/MG (ASSEARA), considerando a entidade de classe como agente responsável pela implantação (Godinho, 2017); e

3) Projeto "Adote uma Casa", onde professores e estudantes da Universidade Vila Velha (UVV) levam assistência técnica às famílias da periferia de Vitória/ES e Vila Velha/ES (NEPCAU/UVV, 2016).

\section{Caso 1: Planta Popular}

O programa "Planta Popular" implementado pela Prefeitura Municipal de Uberlândia/MG desde 2011, consiste em disponibilizar gratuitamente 1(um) projeto arquitetônico, escolhido entre 9 (nove) modelos econômicos com até $70 \mathrm{~m}^{2}$, a famílias de baixa renda com rendimentos de até cinco (5) salários mínimos que tenham apenas 1 (um) imóvel no município, para construção sob regime de mutirão de residências unifamiliares destinadas a uso próprio. 
O programa é sustentável do ponto de vista financeiro, haja vista que ele não precisa de recursos provenientes de verbas públicas para ser concedido aos cidadãos. Todavia, inicialmente foi necessário que a Secretaria Municipal de Planejamento Urbano designasse uma equipe para elaborar os modelos de projetos arquitetônicos dentro das necessidades da população e dos padrões exigidos pelas leis municipais.

\section{Caso 2: Assistência Técnica Pública e Gratuita em Habitação}

A “Assistência Técnica Pública e Gratuita em Habitação” foi implantada no município de Alfenas/MG por meio de uma iniciativa da Associação dos Engenheiros, Arquitetos e Agrônomos da Região de Alfenas/MG (ASSEARA), que firmou um convênio junto a Prefeitura Municipal de Alfenas em 2009 com o objetivo de atender a Lei Federal $\mathrm{n}^{\circ}$ $11.888 / 2008$.

O programa prevê assistência técnica pública e gratuita em habitações unifamiliares de até $70 \mathrm{~m}^{2}$ construídas dentro dos padrões econômicos sob regime de mutirão, abrangendo os serviços de elaboração de projetos, ampliação e reforma, bem como o acompanhamento e execução de obras em conformidade com as exigências da Associação Brasileira de Normas Técnicas (ABNT), do Código de Obras, do Plano Diretor Municipal e da Lei de Parcelamento do Solo. Se necessário, devem ser apresentados o memorial descritivo e a planilha orçamentária. Os serviços também envolvem a regularização de imóveis, porém, neste caso a área da edificação não é limitada. O prazo para finalizar a construção é de no máximo dois anos, período este que corresponde ao prazo de validade do alvará de construção emitido pela prefeitura.

\section{Caso 3: Adote uma Casa}

O programa "Adote uma Casa" consiste em proporcionar assistência técnica gratuita a famílias de baixa renda com rendimentos de até 3 (três) salários mínimos, que possuam 1 (um) imóvel localizado em áreas de interesse social na região da Grande Vitória/ES. Isso se dá por meio de recursos provenientes de parcerias privadas, com o propósito de solucionar por meio da arquitetura e engenharia, problemas relacionados ao conforto ambiental e acessibilidade, contribuindo para melhoria da qualidade de vida da sociedade. A iniciativa já reformou 6 (seis) habitações. 
(CC BY 4.0) | ISSN 2525-3409 | DOI: http://dx.doi.org/10.33448/rsd-v9i7.3770

\subsection{Estratégias de Implantação de Assistência Técnica Pública e Gratuita}

\section{Condição 1: Serviços de Assistência Técnica}

O direito à assistência técnica pública e gratuita abrange todos os serviços de projeto, acompanhamento e execução necessários à edificação, reforma, ampliação e regularização de habitações. Além de assegurar a garantia à moradia digna, a assistência deverá proporcionar o aproveitamento racional do espaço edificado e de seu entorno, bem como dos recursos humanos, técnicos e econômicos disponíveis (Motta, 2011; Soares, 2016).

Os serviços deverão ser formalizados perante o poder público municipal e a ocupação do sítio urbano deverá atender a legislação urbanística e ambiental disposta basicamente na Lei $N^{\circ} 1.357$, de 13 de novembro de 1996, que trata do Parcelamento do Solo Urbano; Lei N$^{\circ}$ 1.358, também de 13 de novembro de 1996, que implementa o Código de Obras; e Lei No 1.686, de 10 de outubro de 2006, que institui o Plano Diretor de João Monlevade/MG. O cumprimento dessas e outras normas evita a ocupação de áreas de risco e preservação ambiental, e propicia qualidade de vida à população.

\section{Condição 2: Habitações de Interesse Social}

As habitações de interesse social correspondem às residências unifamiliares de até $70 \mathrm{~m}^{2}$, construídas sob regime de mutirão, destinadas a uso próprio. Esse perfil de habitação foi definido com base nos estudos de caso, tendo em vista a maior eficácia na redução do déficit habitacional.

\section{Condição 3: Beneficiários}

Os beneficiários finais da assistência técnica pública e gratuita em habitação de interesse social são as famílias com renda mensal de até 3 (três) salários mínimos, residentes em áreas urbanas ou rurais, que possuam apenas 1 (um) imóvel no município de João Monlevade/MG.

Serão atendidas por ordem de cadastro preferencialmente as famílias em situação de risco social, consideradas aquelas que tenham idosos, pessoas com deficiência, mulheres responsáveis pela unidade familiar, e por fim, que se localizem em áreas consideradas de risco, ou seja, impróprias à habitação. 
Todos os requisitos relacionados à renda familiar e posse do imóvel deverão ser comprovados para a concessão do benefício, mediante a apresentação de documentos que serão previamente definidos pelo setor responsável.

\section{Condição 4: Profissionais Legalmente Habilitados}

Os serviços de assistência técnica pública e gratuita serão desenvolvidos por profissionais das áreas de engenharia, arquitetura e urbanismo que estejam legalmente habilitados.

Os conselhos profissionais deverão garantir que todos os serviços sejam dotados de responsabilidade técnica com a finalidade de coibir a atuação de leigos, protegendo a sociedade. Deverão ser firmados convênios entre os agentes e os conselhos, com a finalidade de assegurar a isenção das taxas, dado o interesse público nos serviços de assistência técnica prestados pelos profissionais.

\section{Estratégia 1: Minha Casa Legal}

O projeto "Minha Casa Legal" considerou a Prefeitura Municipal de João Monlevade/MG como o agente responsável pela implantação do projeto. A descrição da estratégia é apresentada no Quadro 1, baseando-se principalmente no "Estudo de Caso 1" referente ao programa "Planta Popular".

A estratégia foi adaptada para atender à "Condição 1", a fim de proporcionar o acesso completo aos serviços de assistência técnica pública, diferentemente do "Estudo de Caso 1", que não oferece o serviço de acompanhamento da execução da obra.

Este projeto foi organizado para ter seu sistema concentrado na Secretaria de Obras, atualmente responsável pela aprovação de projetos e pela fiscalização de obras no município de João Monlevade/MG. O propósito dessa medida foi agilizar o processo de atendimento para concessão do benefício.

Tendo em vista que os projetos serão disponibilizados por meio eletrônico, todos os interessados terão acesso prévio aos modelos para realizarem a escolha anteriormente à solicitação.

A estimativa do número de famílias a serem atendidas foi realizada baseando-se em uma informação verbal da diretoria da ASSEARA sobre a média de projetos arquitetônicos realizados no programa do "Estudo de Caso 2". 


\section{Estratégia 2: Engenharia Pública}

\section{A proposta "Engenharia Pública" define a Entidade de Classe como a principal} agente responsável pela implantação do projeto. A estratégia apresentada no Quadro 2 foi fundamentada no "Estudo de Caso 2" correspondente ao programa "Assistência Técnica Pública e Gratuita em Habitação".

Quadro 1 - Análise dos fatores de viabilidade da estratégia "Minha Casa Legal"

\begin{tabular}{|c|c|c|}
\hline Serviço & \multicolumn{2}{|c|}{$\begin{array}{l}\text { Disponibilizar modelos de projetos arquitetônicos para construção e regularização de } \\
\text { edificações, e acompanhar a execução de obras por meio da realização de pelo menos } \\
\text { (2) duas visitas técnicas por obra. }\end{array}$} \\
\hline Agente & \multicolumn{2}{|c|}{ A Prefeitura Municipal de João Monlevade por meio da Secretaria Municipal de Obras. } \\
\hline Sistema & \multicolumn{2}{|c|}{$\begin{array}{l}\text { Os modelos de projetos arquitetônicos serão disponibilizados em meio eletrônico. A } \\
\text { concessão do benefício será realizada mediante aprovação dos documentos exigidos, a } \\
\text { serem apresentados na Secretaria Municipal. O resultado será informado imediatamente a } \\
\text { fim de possibilitar a escolha modelo e o agendamento da primeira visita técnica. Após o } \\
\text { término da obra, o beneficiado comunicará à Secretaria Municipal o encerramento das } \\
\text { atividades para que, portanto, seja agendada uma nova visita para fiscalização e } \\
\text { expedição do Habite-se, finalizando o processo. }\end{array}$} \\
\hline $\begin{array}{c}\text { Sustentabilidade } \\
\text { Financeira }\end{array}$ & \multicolumn{2}{|c|}{$\begin{array}{l}\text { As despesas serão provenientes do desenvolvimento dos modelos de projetos, suporte } \\
\text { de equipes para o cadastro e seleção de beneficiários, e realização de visitas técnicas. } \\
\text { Contudo, como esses serviços serão executados pelos próprios funcionários da Secretaria } \\
\text { de Obras, os gastos serão inerentes à execução do programa, exigindo verdadeiramente } \\
\text { um melhor aproveitamento dos recursos humanos existentes. } \\
\text { Haverá também a isenção das taxas de Alvará de Construção e Habite-se, e } \\
\text { consequentemente, a Prefeitura dispensará a arrecadação dessas tarifas. }\end{array}$} \\
\hline \multirow{3}{*}{ Escalabilidade } & $1^{\mathrm{a}}$ fase & $\begin{array}{l}\text { Atender até } 15 \text { famílias/mês com a concessão de projetos arquitetônicos. } \\
\text { Utilizar a própria equipe da Secretaria de Obras para aprovação dos } \\
\text { projetos. }\end{array}$ \\
\hline & $2^{\mathrm{a}}$ fase & $\begin{array}{l}\text { Atender até } 20 \text { famílias/mês com a concessão de projetos arquitetônicos } \\
\text { e realização de pelo menos duas (2) visitas técnicas agendadas. Formar } \\
\text { equipes especializadas para realizar o atendimento e acompanhamento } \\
\text { das obras (Engenheiros, Arquitetos e Psicólogos). }\end{array}$ \\
\hline & $3^{\mathrm{a}}$ Fase & $\begin{array}{l}\text { Atender todas as famílias com perfil aprovado, por meio da concessão } \\
\text { de projetos arquitetônicos e realização de pelo menos duas (2) visitas } \\
\text { técnicas agendadas. Abrir escritório especializado em habitação de } \\
\text { interesse social para atendimento à população. }\end{array}$ \\
\hline
\end{tabular}

Fonte: Elaborado pelos autores (2019)

\section{Estratégia 3: Construindo Sonhos}

A estratégia "Construindo Sonhos" adota a Universidade do Estado de Minas Gerais (UEMG), unidade de João Monlevade, como principal responsável pela implantação da proposta. A abordagem apresentada no Quadro 3 inspirou-se no projeto "Adote uma Casa" relacionada ao "Estudo de Caso 3". 
Research, Society and Development, v. 9, n. 7, e167973770, 2020

(CC BY 4.0) | ISSN 2525-3409 | DOI: http://dx.doi.org/10.33448/rsd-v9i7.3770

Esta proposta visa atender a todos os serviços de assistência técnica pública e gratuita conforme estabelecido na "Condição 1", diferentemente do "Estudo de Caso 3", que realiza preferencialmente reformas para regularização de projetos.

A quantidade de famílias a serem atendidas foi estabelecida conforme o número de beneficiários e a previsão de contemplados pelo projeto "Adote uma Casa".

Quadro 2 - Análise dos fatores de viabilidade da estratégia "Engenharia Pública"

\begin{tabular}{|c|c|}
\hline Serviço & $\begin{array}{l}\text { Elaborar projetos arquitetônicos para construção eregularização de edificações, e acompanhar } \\
\text { a execução de obras por meio da realização de pelo menos duas (2) visitas técnicas/obra. }\end{array}$ \\
\hline Agente & $\begin{array}{l}\text { A Entidade de Classe (ex: Associação dos Engenheiros de João Monlevade) e a Prefeitura } \\
\text { Municipal de João Monlevade através da Secretaria Municipal de Obras. }\end{array}$ \\
\hline Sistema & $\begin{array}{l}\text { O cadastro e a seleção das famílias serão realizados pela Entidade de Classe mediante } \\
\text { aprovação dos documentos exigidos e apresentados pelos interessados. Os requerentes serão } \\
\text { informados sobre o resultado da solicitação pela Entidade de Classe, que encaminhará o } \\
\text { serviço para o profissional previamente selecionado por meio de edital. } \\
\text { Após o aceite e recebimento do serviço, será agendada uma reunião entre o profissional e o } \\
\text { cliente para a concepção do programa de necessidades. A reunião será realizada na sede da } \\
\text { Entidade de Classe. Os projetos arquitetônicos serão produzidos e encaminhados para a } \\
\text { Entidade de Classe no prazo de } 30 \text { dias, posteriormente eles serão tramitados para a Secretaria } \\
\text { de Obras. Após a aprovação da Secretaria, será emitido um Alvará de Construção que será } \\
\text { encaminhado para a Entidade de Classe. Logo, o beneficiário será comunicado e poderá } \\
\text { retirar o projeto e o alvará na sede da Entidade. Todo o processo de envio dos projetos e } \\
\text { documentos será realizado via correio eletrônico ou plataforma digital. } \\
\text { O agendamento de pelo menos duas (2) visitas técnicas será realizado através do contato do } \\
\text { próprio profissional com o cliente. O acompanhamento da obra será registrado online pelo } \\
\text { Livro de Ordem eletrônico que funcionará como meio de comprovação do acompanhamento } \\
\text { da construção da edificação. O modelo do Livro de Ordem será disponibilizado pela Entidade } \\
\text { de Classe. Após o registro dos serviços, o pagamento será realizado pela Entidade de Classe } \\
\text { ao profissional. O processo finaliza-se com a expedição do Habite-se pela Secretaria, } \\
\text { mediante solicitação da Entidade de Classe. Ele também poderá ser retirado na sede da } \\
\text { Entidade de Classe. }\end{array}$ \\
\hline $\begin{array}{l}\text { Sustentabilidade } \\
\text { Financeira }\end{array}$ & $\begin{array}{l}\text { A realização do projeto está condicionada à provisão de recursos vindos de terceiros. Eles } \\
\text { poderão ser originados, por exemplo, por meio de chamamentos públicos, leis orçamentárias, } \\
\text { emendas parlamentares, patrocínios e doações. Será realizado um convênio entre a Prefeitura } \\
\text { de João Monlevade e a Entidade de Classe para estabelecimento de uma parceria visando a } \\
\text { aprovação dos projetos e expedição de Alvará de Construção e Habite-se via meio eletrônico, } \\
\text { isentando os beneficiários da cobrança de taxas e, portanto, dispensando essa parcela da } \\
\text { arrecadação. } \\
\text { Os recursos serão utilizados para o pagamento de funcionários e estagiários, despesas de } \\
\text { manutenção da entidade, e atividades executadas pelos profissionais. Os valores pagos pelos } \\
\text { serviços serão divulgados no edital de seleção dos profissionais. Visto que o projeto é sem } \\
\text { fins lucrativos, os preços corresponderão à estimativa dos custos. }\end{array}$ \\
\hline Escalabilidade & $\begin{array}{l}\text { A escalabilidade deste projeto está diretamente ligada à disponibilidade dos recursos } \\
\text { financeiros. O número de famílias atendidas é proporcional à captação de investimentos. }\end{array}$ \\
\hline
\end{tabular}
Fonte: Elaborado pelos autores (2019). 
Quadro 3 - Análise dos fatores de viabilidade da estratégia "Construindo Sonhos".

\begin{tabular}{|c|c|c|}
\hline Serviço & \multicolumn{2}{|c|}{$\begin{array}{l}\text { Elaborar projetos arquitetônicos para construção e regularização de edificações, } \\
\text { realizar o acompanhamento e a execução de obras. }\end{array}$} \\
\hline Agente & \multicolumn{2}{|c|}{$\begin{array}{l}\text { A Universidade do Estado de Minas Gerais (ex: Núcleo de Estudos), os parceiros } \\
\text { institucionais (ex: Prefeitura Municipal de João Monlevade, associação de moradores } \\
\text { etc.) e os parceiros estratégicos (empresas privadas etc.). }\end{array}$} \\
\hline Sistema & \multicolumn{2}{|c|}{$\begin{array}{l}\text { As famílias serão selecionadas pelo Núcleo de Estudos por meio de visita a área de } \\
\text { interesse social a ser indicada pelos parceiros institucionais. O benefício será } \\
\text { concedido mediante aprovação da documentação exigida. } \\
\text { Inicialmente, serão realizadas visitas técnicas para a coleta de dados e concepção do } \\
\text { programa de necessidades. Os projetos arquitetônicos serão desenvolvidos pelos } \\
\text { estudantes, orientados, supervisionados pelos professores, e aprovados pelos } \\
\text { beneficiários. O Núcleo de Estudos encaminhará os projetos para a Prefeitura, e } \\
\text { mediante a expedição do Alvará de Construção será iniciada a obra. A execução será } \\
\text { acompanhada pelo Núcleo e realizada sob regime de mutirão. Após a conclusão,o } \\
\text { Núcleo solicitará a expedição do Habite-se que será entregue ao beneficiário, } \\
\text { finalizando o processo. }\end{array}$} \\
\hline $\begin{array}{l}\text { Sustentabilidade } \\
\text { Financeira }\end{array}$ & \multicolumn{2}{|c|}{$\begin{array}{l}\text { As despesas serão referentes aos custos provenientes do desenvolvimento das } \\
\text { atividades pelo Núcleo de Estudos, que poderão ser subsidiadas por bolsas de estudos } \\
\text { (FAPEMIG e CNPq) concedidas pelo governo a projetos de extensão, e/ou } \\
\text { investimentos de empresas privadas. } \\
\text { Os materiais de construção serão doados por parceiros estratégicos, e/ou serão } \\
\text { adquiridos por meio de recursos financeiros obtidos através de vaquinhas online. } \\
\text { Haverá também a isenção das taxas de Alvará de Construção e Habite-se, e } \\
\text { consequentemente, a Prefeitura dispensará a arrecadação dessas tarifas. }\end{array}$} \\
\hline \multirow{3}{*}{ Escalabilidade } & $1^{\mathrm{a}}$ fase & $\begin{array}{l}\text { Atender } 1 \text { família/semestre. Os serviços serão realizados apenas pelo } \\
\text { Núcleo de Estudos. }\end{array}$ \\
\hline & $2^{a}$ fase & $\begin{array}{l}\text { Atender } 2 \text { famílias/semestre. Serão formadas equipes especializadas } \\
\text { (engenheiros, arquitetos e psicólogos) em parceria com outras } \\
\text { instituições de ensino para realização dos atendimentos. }\end{array}$ \\
\hline & $3^{a}$ fase & $\begin{array}{l}\text { Atender } 5 \text { famílias/semestre. Expansão da equipe especializada. } \\
\text { Abertura de escritório externo de habitação de interesse social para } \\
\text { atendimento à população. }\end{array}$ \\
\hline
\end{tabular}

Fonte: Elaborado pelos autores (2019)

\section{Considerações Finais}

Os estudos sobre os programas "Planta Popular", "Assistência Técnica Pública e Gratuita em Habitação" e "Adote uma Casa", fundamentaram as propostas de implantação de assistência técnica pública e gratuita a famílias de baixa renda e habitações no município de João Monlevade/MG. Utilizou-se de análises dos mecanismos adotados, permitindo assim a formulação de estratégias com sistemas mais eficientes e atendimentos mais rápidos.

É importante salientar que nenhum dos projetos foi executado mediante apoio financeiro da União aos Estados e aos Municípios, conforme garantido pelo artigo $3^{\circ}$ da Lei Federal $n^{\circ} 11.888$, de 24 de dezembro de 2008, constatando a ineficácia do poder público nas ações de efetivação das políticas habitacionais. 
O objetivo deste estudo foi alcançado e demonstrado principalmente por meio da apresentação das estratégias "Minha Casa Legal", "Engenharia Pública" e "Construindo Sonhos". O processo de concepção desses projetos buscou atender ao direito à assistência técnica preconizado no artigo $2^{\circ}$ da Lei Federal $n^{\circ} 11.888$. O sistema social proposto pela legislação para o auxílio à construção de habitações foi adaptado à realidade do município de João Monlevade com o propósito de possibilitar a sua concretização.

O projeto "Minha Casa Legal" foi considerado como a estratégia mais adequada e consistente, pois possibilita o acesso à assistência técnica pública e gratuita em maior escala para a população de baixa renda, apesar de todas as estratégias serem passíveis de implantação.

O projeto "Engenharia Pública", por sua vez, depende essencialmente do engajamento de seus agentes para a provisão de recursos financeiros, necessitando de grande esforço e planejamento para sua execução, o que torna sua viabilização trabalhosa e dificultosa.

Finalmente, o programa "Adote uma Casa" tem sua expansão ao atendimento em maior escala restrito, uma vez que, o agente principal é um núcleo de estudos composto por professores e alunos e, portanto, é considerado como uma atividade de extensão à universidade. Além disso, a implementação também depende de parceiros estratégicos para o fornecimento de materiais de construções e recursos financeiros. Porém, diferentemente das outras propostas, a assistência é completa, pois abrange os serviços desde a elaboração dos projetos até a entrega da edificação para os beneficiários, garantida o acesso à moradia.

Por último, foi possível averiguar que os serviços de engenharia, arquitetura e urbanismo executados por profissionais legalmente habilitados refletem no cumprimento da legislação urbanística e ambiental, diminuindo as despesas com problemas relacionados à infraestrutura urbana, bem como, combatem aos elevados índices de déficit habitacional e de autoconstrução existentes, garantindo segurança e qualidade de vida à população.

\section{Referências}

ABNT NBR 14274 (2011). Informação e documentação - Trabalhos Acadêmicos Apresentação. Associação Brasileira de Normas Técnicas. Rio de Janeiro. Disponível em: <http://site.ufvjm.edu.br/revistamultidisciplinar/files/2011/09/NBR_14724_ atualizada_abr_2011.pdf>. Acesso em: 30 abril 2020. 
Aravena, A. (2017). Clássico da Arquitetura. [s.1]. Website Daniel Carvalho Arquitestos. Disponível em: <http://www.danielcarvalhoarq.com/newblog/2017/2/3/frase-alejandroaravena>. Acesso em: 29 abril 2020.

Azevedo, S. (1996). A crise da política habitacional: dilemas e perspectivas para o final dos anos 90. In. Azevedo, Sérgio de; Andrade, Luis Aureliano G. de (orgs.). A crise da moradia nas grandes cidades - da questão da habitação à reforma urbana. Rio de Janeiro: Editora UFRJ.

Andrade, L. A. G. (1982). Habitação e poder - da Fundação da Casa Popular ao Banco Nacional de Habitação. Rio de Janeiro: Zahar Editores.

Brasil. (2000). Constituição (1988). Emenda Constitucional No 26, de 14 de Fevereiro de 2000. Altera a redação do art. $6^{\mathrm{O}}$ da Constituição Federal. Brasília.

Disponível em: <http://www.planalto.gov.br/ccivil_03/Constituicao/

Constituicao.htm>. Acesso em: 29 abr. 2020.

Brasil. (1993). Lei No 8.677, de 13 de Julho de 1993. Dispõe sobre o Fundo de Desenvolvimento Social, e dá outras providências. Brasília, 1993. Disponível em: <http://www.planalto.gov.br/ccivil_03/Leis/L8677.htm>. Acesso em: 29 abril 2020.

Brasil. (1987). Lei No 9.636, de 15 de Maio de 1998. Dispõe sobre a regularização, administração, aforamento e alienação de bens imóveis de domínio da União, altera dispositivos dos Decretos-Leis nos 9.760, de 5 de setembro de 1946, e 2.398, de 21 de dezembro de 1987, regulamenta o § 2 o do art. 49 do Ato das Disposições Constitucionais Transitórias, e dá outras providências. Brasília, 1988. Disponível em: <http://www.planalto.gov.br/ccivil_03/leis/19636.htm>. Acesso em: 29 abril 2020.

Brasil. (2001). Lei No 10.257, de 10 de Julho de 2001. Regulamenta os arts. 182 e 183 da Constituição Federal estabelecem diretrizes gerais da política urbana e dá outras providências. Brasília. Disponível em: 
<http://www.planalto.gov.br/ccivil_03/LEIS/LEIS_2001/L10257.htm>. Acesso em: 30 abril 2020.

Brasil. (2005). Lei № 11.124, de 16 de Junho de 2005. Dispõe sobre o Sistema Nacional de Habitação de Interesse Social - SNHIS, cria o Fundo Nacional de Habitação de Interesse Social - FNHIS e institui o Conselho Gestor do FNHIS. Brasília, 2005. Disponível em: <http://www.planalto.gov.br/ccivil_03/_Ato20042006/2005/Lei/L11124.htm>. Acesso em: 30 abril 2020.

Brasil. (2008). Lei $\mathrm{N}^{\circ} 11.888$, de 24 de Dezembro de 2008. Assegura às famílias de baixa renda assistência técnica pública e gratuita para o projeto e a construção de habitação de interesse social e altera a Lei no 11.124, de 16 de junho de 2005. Brasília, 2008. Disponível em: <http://www.planalto.gov.br/ccivil_03/_Ato20072010/2008/Lei/L11888.htm>. Acesso em: 30 abril 2020.

Brasil. (2014). Conselho das Cidades. Brasília. Ministério do Desenvolvimento Regional. Disponível em: 〈http://www.cidades.gov.br/conselho-das-cidades〉. Acesso em: 30 abril 2020.

Brasil. (2019). Ministério do Desenvolvimento Regional. Ministério do Desenvolvimento Regional (MDR). Brasília, 2019. Disponível em: <http://www.cidades.gov.br/institucional>. Acesso em: 30 abril 2020.

Brasil. (2019). Ministério do Desenvolvimento Regional. Mais de 980 mil pessoas receberam novas moradias em 300 dias de governo. Brasília, 2019. Disponível em: $<$ http://www.cidades.gov.br/ultimas-noticias/12414-mais-de-980-mil-pessoasreceberam-novas-moradias-em-300-dias-de-governo>. Acesso em: 29 abril 2020.

Brasil. (2014). Ministério do Desenvolvimento Regional. Plano Nacional de Habitação - PlanHab. Brasília. Disponível em: $<$ http://www.cidades.gov.br/habitacao-cidades/plano-nacional-de-habitacaoplanhab>. Acesso em: 30 abril 2020. 
Brasil. (2014). Sistema Nacional de Habitação de Interesse Social. Brasília, Ministério do Desenvolvimento Regional. Disponível em:

$<$ http://www.cidades.gov.br/habitacao-cidades/sistema-nacional-de-habitacao-deinteresse-social>. Acesso em: 30 abril 2020.

Cardoso, P. (2008). Sistema nacional de habitação de interesse social à luz do novo marco legal urbanístico. Subsídios para implementação nos estados e municípios. Lei federal no 11.124/05. São Paulo: Instituto Pólis. Disponível em: <http://www.polis. org.br/uploads/952/952.pdf>. Acesso em: 29 abril 2020.

CAU/BR (2015). Conselho de Arquitetura e Urbanismo do Brasil; Instituto DataFolha. Pesquisa inédita: Percepções da sociedade sobre Arquitetura e Urbanismo. [s.1.]. Disponível em: <https://www.caubr.gov.br/pesquisa-caubr-datafolha-revela-visoes-da-sociedade-sobrearquitetura-e-urbanismo/>. Acesso em: 28 abril 2020.

CAU/MG (2009). Conselho Regional de Engenharia, Arquitetura e Agronomia de Minas Gerais. Assistência Técnica: direito de todos! O ato de morar é o ato fundamental da vida humana. Belo Horizonte, 2009. Disponível em: <http://www.creamg.org.br/images/cartilhas/Assistencia-Tecnica---um-direito-de-todos.pdf>. Acesso em: 30 abril 2020.

CAU/SC (2018). Conselho de Arquitetura e Urbanismo do Brasil; Conselho de Arquitetura e Urbanismo de Santa Catarina; Assistência Técnica de Habitação de Interesse Social (ATHIS). Um direito e muitas possibilidades. Brasília. Disponível em: <http://www.caubr.gov.br/wp-content/uploads/2018/12/nova-cartilha.pdf>. Acesso em: 29 abril 2020.

Centro de Informação das Nações Unidas no Brasil (2009). Declaração Universal dos Direitos Humanos. Rio de Janeiro. Disponível em: <https://nacoesunidas.org/wpcontent/uploads/2018/10/DUDH.pdf>. Acesso em: Acesso em: 29 abril 2020.

CREA/MG (2019). Conselho Regional de Engenharia e Agronomia de Minas Gerais. Anotação de Responsabilidade Técnica. [s.1.], [s.d.]. Disponível em: <http://www.crea- 
mg.org.br/ index.php/servicos/indice-de-servicos/anotacao-de-responsabilidade-tecnica-a-rt>. Acesso em: 03 jun. 2019.

FGV (2018). Fundação Getúlio Vargas. Análise das Necessidades Habitacionais e suas Tendências para os Próximos Dez Anos. Relatório Técnico Final - 2ª Versão. [s.l.].

Disponível em: <https://www.abrainc.org.br/wp-content/uploads/2018/10/ ANEHAB-Estudocompleto.pdf>. Acesso em: 30 abril 2020.

FJP (2016). Fundação João Pinheiro; Diretoria de Estatísticas e Informações. Déficit Habitacional no Brasil 2015. Belo Horizonte. Disponível em: <http://fjp.mg.gov.br/index. php/ docman/direi-2018/785-serie-estatistica-e-informacoes-n06-deficit-habitacional-nobrasil-2015/file>. Acesso em: 29 abril 2020.

Gerhardt, T. E. (Org.) \& Silveira, D. T. (Org.) (2009). Métodos de Pesquisa. Porto Alegre: Editora da UFRGS. Disponível em: <http://www.ufrgs.br/cursopgdr/ downloads Serie/ derad005.pdf>. Acesso em: 18 nov. 2019.

Gil, A. C. (2008). Métodos e Técnicas de Pesquisa Social. São Paulo: Atlas, $6^{\text {a }}$ ed. Disponível em: <https://ayanrafael.files.wordpress.com/2011/08/gil-a-c-mc3a9todos-e-tc3a9cnicas-depesquisa-social.pdf>. Acesso em: 28 abril 2020.

Godinho, I. M. A. (2017). Análise da Implementação da Assistência Técnica Pública e Gratuita em Habitação no Município de Alfenas - MG. UFV, Viçosa. Disponível em:<http://www.locus.ufv.br/bitstream/handle/123456789/18073/texto\%20completo.pdf? sequence $=1 \&$ isAllowed=y $>$. Acesso em: 30 abril 2020.

IBGE. (2010). Censo Demográfico. Instituto Brasileiro de Geografia e Estatística - IBGE [s.l.]. Disponível em: <https://cidades.ibge.gov.br/brasil/mg/joao-monlevade/pesquisa/ 23/25207?tipo=ranking>. Acesso em: 29 abril 2020.

IBGE. (2017). João Monlevade. [s.l.]. Instituto Brasileiro de Geografia e Estatística (IBGE). Disponível em: <https://cidades.ibge.gov.br/brasil/mg/joao-monlevade/panorama>. Acesso em: 29 abril 2020. 
IBGE. (2017). Pesquisa de Informações Básicas Municipais. [s.1.] (2017). Instituto Brasileiro de Geografia e Estatística (IBGE). Disponível em:

<https://cidades.ibge.gov.br/brasil/mg/joao-monlevade/pesquisa/1/21682>. Acesso em: 30 abril 2020.

IAB (2010). Instituto dos Arquitetos do Brasil. Manual para a Implantação da Assistência Técnica Pública e Gratuita a Famílias de Baixa Renda para Projeto e Construção de Habitação de Interesse Social. Ed. Tecnodata Educacional, [s.1.]. Disponível em: <http://www.itpacporto.com.br/arquivos/EMAU/manual-para-implantacao-da-assistenciatecnica-publica-e-gratuiata.pdf>. Acesso em: 28 abril 2020.

João Monlevade (2003). Lei $N^{o} 1.572$, de 15 de Abril de 2003. João Monlevade. Disponível em: <http://12fsistemasweb.com.br/pmjm.mg.gov.br/uploads/legislacao/ \%7BA17EB206BD4A-3BB4-5AB3-E213EAADD4E6\%7D.pdf>. Acesso em: 28 abril 2020.

Lis, L. (2019). Minha Casa Minha Vida completa 10 anos com queda nas contratações. [s.1.]. Disponível em: <https://g1.globo.com/economia/noticia/2019/03/25/minha-casa-minha-vidacompleta-10-anos-com-queda-nas-contratacoes.ghtml>. Acesso em: 29 abril 2020.

Motta, L. D. (2011). A Questão da Habitação no Brasil: Políticas Públicas, Conflitos Urbanos e o Direito à Cidade. Minas Gerais. Disponível em: https://conflitosambientaismg.lcc.ufmg.br/wp-content/uploads/2014/04/TAMCMOTTA_Luana_-_A_questao_da_habitacao_no_Brasil.pdf. Acesso em: 30 abril 2020.

NEPCAU/UVV (2016). Núcleo de Estudos e Práticas dos Cursos de Arquitetura e Urbanismo da Universidade Vila Velha/ES. Design de Produto e Engenharia Civil. Adote uma Casa. Um projeto NEP e UVV. Vila Velha. Disponível em: https://adoteumacasa.wixsite.com/oprojeto>. Acesso em: 30 abril 2020.

Nicolau, A. R. (2018). Adote uma Casa. Vila Velha. Disponível em: <https://www.causc.gov.br/wp-content/uploads/2019/01/2018_11_06_MESA-3_Adote-umaCasa-ES_Alexandre-Nicolau.pdf>. Acesso em: 29 abril 2020. 
ONU/BR (2016). Organização das Nações Unidas Brasil. Moradia adequada deve estar no centro das políticas urbanas, diz ONU no Dia Mundial do Habitat. [s.1.].

Disponível em: <https://nacoesunidas.org/moradia-adequada-deve-estar-no-centro-daspoliticas-urbanas-diz-onu-no-dia-mundial-do-habitat/>. Acesso em: 28 abril 2020.

PMJM/MG (2013). Prefeitura Municipal de João Monlevade/MG. Prefeitura de Monlevade apresenta plano local de habitação. João Monlevade. Disponível em:

<https://www.pmjm.mg. gov.br/noticiasView/7276_Prefeitura-de-Monlevade-apresentaplano-local-de habitacao.html>. Acesso em: 30 abril 2020.

PMU/MG (2017). Prefeitura Municipal de Uberlândia. Secretaria Municipal de Planejamento Urbano. Manual Simplificado da Planta Popular. Uberlândia. Disponível em: <http://servicos.uberlandia.mg.gov.br/uploads/cms_b_arquivos/18404.pdf>. Acesso em: 30 abril 2020.

Soares, C. J. F. (2016). Direito à Moradia e Políticas Públicas Habitacionais: uma crítica da atuação do Estado na efetivação do direito fundamental. Belo Horizonte: FUMEC/Minas. Disponível em: <http://www.fumec.br/revistas/pdmd/article/view/ 5055/2605>. Acesso em: 30 abril 2020.

UEMG/JM (2019). Universidade do Estado de Minas Gerais. Unidade João Monlevade. [s.1.]. Disponível em: <http://www.uemg.br/unidades-2019/162-joao-monlevade>. Acesso em: 29 abril 2020.

UEMG/JM. Universidade do Estado de Minas Gerais. Unidade João Monlevade. Engenharia Civil. [s.l.], [s.d.]. Disponível em: <http://www.faenge.uemg.br/eng_civil.php>. Acesso em: 30 abril 2020.

Porcentagem de contribuição de cada autor no manuscrito

Thainá Prando Basto $-70 \%$

Almir Antônio Vieira - 30\% 